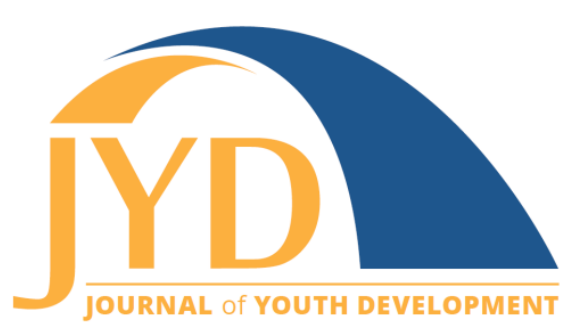

http://jyd.pitt.edu/ | Vol. 15 Issue 3 DOI 10.5195/jyd.2020.945 | ISSN 2325-4017 (online)

\title{
Preventing Bullying: Consequences, Prevention, and Intervention
}

\author{
Suzanne Le Menestrel \\ National Academies of Sciences, Engineering, and Medicine \\ slemenestrel@nas.edu
}

\begin{abstract}
Bullying is considered to be a significant public health problem with both short- and long-term physical and social-emotional consequences for youth. A large body of research indicates that youth who have been bullied are at increased risk of subsequent mental, emotional, health, and behavioral problems, especially internalizing problems, such as low self-esteem, depression, anxiety, and loneliness. Given the growing awareness of bullying as a public health problem and the increasing evidence of short-and longterm physical, mental, emotional, and behavioral health and academic consequences of bullying behavior, there have been significant efforts at the practice, program, and policy levels to address bullying behavior. This article summarizes a recent consensus report from the National Academies of Sciences, Engineering, and Medicine, Preventing Bullying Through Science, Policy, and Practice, and what is known about the consequences of bullying behavior and interventions that attempt to prevent and respond to it.
\end{abstract}

Key words: bullying prevention, bullying, victimization, interventions, programs

\section{Introduction}

In 2016, the National Academies of Sciences, Engineering, and Medicine (the National Academies) released a consensus study report to compile the scientific evidence on the consequences of bullying and factors that promote resilient outcomes for both children and youth who bully and those who are bullied. The resulting report, Preventing Bullying Through Science, Policy, and Practice, authored by the Committee on the Biological and Psychosocial Effects of Peer Victimization: Lessons for Bullying Prevention (National Academies, 2016), offers concrete recommendations for intervening in and preventing bullying for youth, parents,

(cc) $\mathbf{E Y}$ New articles in this journal are licensed under a Creative Commons Attribution 4.0 License. This journal is published by the University Library System, University of Pittsburgh and is cosponsored by the University of Pittsburgh Press. The Journal of Youth Development is the official peer-reviewed publication of the National Association of Extension 4-H Agents and the National AfterSchool Association. 
educators, and youth workers. ${ }^{1}$ Bullying is now recognized as a major and preventable public health problem that can have long-lasting consequences (McDougall \& Vaillancourt, 2015; Wolke \& Lereya, 2015).

\section{Defining Bullying}

Bullying is defined by the Centers for Disease Control and Prevention and the U.S. Department of Education as "any unwanted aggressive behavior(s) by another youth or group of youths who are not siblings or current dating partners that involves an observed or perceived power imbalance and is repeated multiple times or is highly likely to be repeated." Bullying may inflict harm or distress on the targeted youth including physical, psychological, social, or educational harm (Gladden et al., 2014, pg. 7). In this particular definition, bullying is differentiated from other types of harassment or interpersonal violence by the "perceived" or "observed" power imbalance, the occurrence of bullying among youth or groups of youths rather than between adults and youth, and the repetition.

There are four main types of bullying (Gladden et al., 2014): (a) Physical bullying involves the use of physical force (such as shoving, hitting, spitting, pushing, and tripping); (b) Verbal bullying involves words or writing that cause harm (such as taunting, name-calling, offensive notes or hand gestures, verbal threats); (c) Relational bullying is behavior designed to harm the reputation and relationships of the targeted youth (such as social isolation, rumor-spreading, posting mean comments or pictures online); and (d) Damage to property, theft or damaging of the target youth's property by the bully in order to cause harm. Cyberbullying is not a separate

\footnotetext{
${ }^{1}$ This article reproduces text verbatim and paraphrases Preventing Bullying Through Science, Policy, and Practice released in 2016 and used with permission from the National Academies Press, Washington, DC. Suggested citation for the full report: National Academies of Sciences, Engineering, and Medicine. 2016. Preventing Bullying Through Science, Policy, and Practice. Washington, DC: The National Academies Press. https://doi.org/10.17226/23482. The report was authored by the Committee on the Biological and Psychosocial Effects of Peer Victimization: Lessons for Bullying Prevention. Appreciation goes to Fred Rivara, Jonathan Todres, and Natacha Blain for their reviews of earlier drafts of this article and to the committee for authoring the full report. This study was funded by the Centers for Disease Control and Prevention; the Eunice Kennedy Shriver National Institute of Child Health and Human Development; the Health Resources and Services Administration; the Highmark Foundation; the National Institute of Justice; the Robert Wood Johnson Foundation; the Semi J. and Ruth W. Begun Foundation; and the Substance Abuse and Mental Health Services Administration.
} 


\section{Preventing Bullying}

type of bullying, but a way in which some types of bullying can happen. For example, verbal bullying and relational bullying can happen online.

Bullying can happen as early as preschool but is most likely to happen during middle school. Children are more or less likely to be involved in specific forms of bullying at different ages, depending on their verbal, cognitive, and social development (Limber, 2014). For example, youths' increasing access to technology as they age may help explain rising rates of cyberbullying as youth age. Bullying can also happen in many different settings-in classrooms, in school gyms and cafeterias, in afterschool programs, on school buses, and online.

\section{Cyberbullying}

Outside of school, the online world is among the most common public "places" where youth spend their time. Social media platforms are used by the majority of youth and provide them with opportunities to stay connected to friends, develop an online identity, and seek information about peers. There have been studies to show that peer interactions online can be just as important for self-esteem and friendships as those expressed offline (Valkenburg \& Peter, 2011).

There is evidence that being bullied online is associated with being bullied in person (Ybarra \& Mitchell, 2004). Online tools are popular and are available 24/7 using mobile devices. Thus, these technologies present both new opportunities and challenges to youth as they navigate relationships, social situations, and bullying behavior.

\section{Bullying as a Group Phenomenon}

Bullying has been characterized as a "group phenomenon" with multiple peers taking on different roles in addition to the perpetrator-target dyad (Olweus, 1993b, 2001; Salmivalli, 2001, 2010, 2014). The four major participant roles in typical bullying episodes include, in addition to perpetrators and targets:

- assistants

- reinforcers

- defenders

- bystanders

Assistants are youth who help the perpetrator of the bullying once the episode has begun. Reinforcers are those who show signs of approval of the bullying by laughing or showing other 
indications of encouragement. Defenders are youth who actively come to the aid of the target of bullying. Bystanders or onlookers are those who observe the bullying event but play a passive role in the bullying dynamic. As bystanders move from middle school to high school, they become even more passive (Marsh et al., 2011; Pöyhönen et al., 2010; Trach et al., 2010). Given their potential to either prevent or reinforce bullying behavior, of the four additional participant roles described above, bystanders have been the focus of most participant role research.

\section{Youth Who are Vulnerable to Being Bullied}

There are specific groups of youth who are more vulnerable to being bullied including youth who have a disability; youth who are overweight or obese; and youth who identify as lesbian, gay, bisexual, transgender, or queer (LGBTQ). Other vulnerable groups, including youth who are immigrants, those from a lower socioeconomic status, youth with a minority religious affiliation, and youth with intersectional identities (i.e., youth with multiple stigmatized statuses such as a Black, lesbian youth) may also be at heightened risk of being bullied, The available research on vulnerable groups is in its early stages and there is insufficient evidence to say whether these groups are targeted disproportionately by bullying behavior. At any rate, there is a lack of nationally representative data on these and other vulnerable groups and more research is needed to produce representative estimates of bullying, including bias-based and discriminatory bullying.

\section{Consequences of Bullying}

Bullying is a serious public health problem but has long been tolerated by many people as a rite of passage among children and teens. However, bullying is not a normal part of childhood and harms the child who is bullied, the child who bullies, and the bystanders. Below are summaries of the consequences for each of these categories of youth.

\section{Consequences for Youth Who are Bullied}

A large body of research indicates that individuals who have been bullied are at increased risk of subsequent mental, emotional, health, and behavioral problems, especially internalizing problems, such as low self-esteem, depression, anxiety, and loneliness (Gini \& Pozzoli, 2009; Lereya et al., 2015; Reijntjes et al., 2010; Ttofi et al., 2011). Moreover, there is a growing body of research that has shown that youth who are bullied are at increased risk for poor academic 


\section{Preventing Bullying}

achievement (Beran, 2009; Beran et al., 2008; Beran \& Lupart, 2009; Glew et al., 2005; Nakamoto \& Schwartz, 2010; Neary \& Joseph, 1994) and increased absenteeism (Juvonen et al., 2000; Kochenderfer \& Ladd, 1996; Vaillancourt et al., 2013).

Also, emerging evidence suggests that repeated exposure to bullying may produce a neural signature that could underlie some of the behavioral outcomes associated with being bullied. Although the effects of being bullied on the brain are not yet fully understood, there are changes in the stress response system in the brain that are associated with increased risk for mental health problems, cognitive function, self-regulation, and other physical health problems. The long-term consequences of being bullied extend into adulthood.

\section{Consequences for Youth Who Bully Others}

Individuals who bully others are likely to experience negative emotional, behavioral, and mental health outcomes. Several studies have focused on the consequences of bullying. However, most research has not distinguished the perpetration of bullying from other forms of peer aggression. Some youth who bully others do so because they have some form of maladjustment (Olweus, 1993a) or are motivated by establishing their status in a social network (Faris \& Ennett, 2012; Rodkin et al., 2015; Sijtsema et al., 2009; Vaillancourt et al., 2003).

There is also a stereotype of youth who bully as possessing few assets, being socially inept and having psychopathic tendencies. Whereas there are some cases of the "classic" or "stereotypical" bully, when research has examined the role of social status, they find that most youth who bully others have considerable power within their peer networks and that "highstatus" perpetrators tend to be seen by peers as popular, socially skilled, and leaders (de Bruyn et al., 2010; Dijkstra et al., 2008; Peeters et al., 2010; Thunfors \& Cornell, 2008; Vaillancourt et al., 2003).

High-status bullies have also been found to rank high on assets and competencies that the peer group values such as being attractive or being good athletes (Farmer et al., 2003; Vaillancourt et al., 2003); They have also been found to rank low on psychopathology and to use aggression instrumentally to achieve and maintain their domination (for reviews, see Rodkin et al., 2015, and Vaillancourt et al., 2010b). Considering these findings of contrasting characteristics of perpetrators of bullying behavior, it makes sense that the research on outcomes of perpetrating is mixed. Unfortunately, most research on the short- and long-term outcomes of perpetrating 


\section{Preventing Bullying}

bullying behavior has not taken into account this heterogeneity when considering the impact on children and youth who have bullied their peers.

Nevertheless, there are findings from cross-sectional studies that youth who bullied others are at risk of developing psychosomatic problems. For example, in a meta-analysis of six studies, Gini and Pozzoli (2009) found that children who bully had a higher risk of exhibiting psychosomatic problems than their peers who were not involved in bullying. Moreover, Wolke and colleagues (2014) reported that among a sample of 4,720 children ages 8 to 11 , both children who are bullied and children who bullied others had a higher prevalence of psychotic experiences at age 18. In sum, the bulk of the research on the prevalence of bullying behavior focuses almost entirely on the children who are bullied. More longitudinal studies are needed in order to understand the short- and long-term health, psychosocial, and academic consequences for children and youth who bully others.

\section{Consequences for Youth Who Both Bully Others and Are Bullied}

Youth who both bully others and are themselves bullied appear to be at greatest risk for poor psychosocial outcomes, compared to those who only bully or are only bullied and to those who are not bullied. Youth who both bully and are bullied experience externalizing (e.g., aggression) and internalizing problems (e.g., psychosomatic complaints), negative perception of self and others, poor social skills, and rejection by their peer groups. Adolescents who were involved in cyberbullying as both perpetrators and targets are most at risk for negative mental and physical health consequences, compared to those who were only perpetrators, those who were only targets, or those who were bystanders (Kowalski \& Limber, 2013; Nixon, 2014).

\section{Consequences for Youth Who are Bystanders}

Bullying frequently occurs in the presence of youth who are passive witnesses or bystanders. Although there is more research on bystanders than the other actors in a bullying episode (i.e., assistants, defenders, and reinforcers), there is still very limited research on the consequences of witnessing bullying for youth who are bystanders. There is some evidence that bystanders have elevated mental health and substance use risks (Rivers \& Noret, 2013; Rivers et al., 2009), as well as feelings of anxiety and insecurity (e.g., Rigby \& Slee, 1993), which is related to a fear of retaliation (Musher-Eizenman et al., 2004). Most of the limited research available on the consequences of bullying for youth who are bystanders is focused on understanding the 
bystanders' motives and why they do or do not intervene. More research is needed on the emotional and psychological impact of witnessing bullying.

\section{Addressing Bullying}

Given the growing awareness of bullying as a public health problem and the increasing evidence of short- and long-term physical, mental, emotional, and behavioral health and academic consequences of bullying behavior, there have been significant efforts at the practice, program, and policy levels to address bullying behavior. At the federal level, the Federal Partners in Bullying Prevention Steering Committee, co-led by the U.S. Departments of Health and Human Services and Education, coordinate policy, research, and programs on bullying. These agencies support the website, www.stopbullying.gov, which provides resources from relevant federal agencies targeted toward understanding what bullying is, how to stop and/or prevent it and understand who may be at the greatest risk of being engaged in bullying behavior.

\section{Laws and Policies}

At the policy level, there is no specific federal law on bullying. Federal law and policy do provide a framework for many of the responses to bullying and offers protections and remedies for certain individuals. For example, federal civil rights and anti-discrimination laws offer important protections against bullying but may be limited in addressing bullying of individuals who are not a member of an enumerated protected class, such as LGBTQ youth. State and local law and policy constitute a key component of current responses to bullying. There is substantial variation across states and state laws differ on some critical issues, such as definitions of bullying and the scope of the schools' authority to respond to bullying. Also, legal definitions sometimes differ from definitions used in research and anti-bullying programs. Stopbullying.gov provides a state by state overview of laws and policies as of $2018 .^{2}$

There is emerging evidence that suggests anti-bullying laws and policies can have a positive impact on reducing bullying and on protecting groups that are disproportionately vulnerable to bullying, such as gay and lesbian youth. For example, Hatzenbuehler and Keyes (2013) found that peer harassment and victimization of all youth, including those who were heterosexual, and those who were lesbian, gay, or bisexual, was less likely to occur in counties in Oregon with a greater proportion of school districts with inclusive anti-bullying policies (those that included

\footnotetext{
${ }^{2}$ See https://www.stopbullying.gov/laws/index.html
} 


\section{Preventing Bullying}

sexual orientation as a protected class). The development of model anti-bullying laws or policies should be evidence-based; however, additional research is needed to determine those specific components of an anti-bullying law that are most effective in reducing bullying, to guide legislators who may amend existing laws or create new ones.

\section{Prevention and Intervention Programs}

Systematic reviews of the literature and meta-analyses conducted over the past decade recommend that the most effective bullying prevention programs are whole school, multicomponent programs that combine elements of universal and targeted strategies (Bradshaw, 2015; Rigby \& Slee, 2008; Vreeman \& Carroll, 2007). Universal programs or strategies (Institute of Medicine, 1994) are those that are aimed at reducing risks and strengthening skills for all youth within a defined community or school setting. Examples of universal programs or strategies include social-emotional lessons used in the classroom, counselors coming into the classroom to model strategies for responding to or reporting bullying, and holding classroom meetings to discuss issues related to bullying or equity. Most of the bullying prevention programs that have been evaluated with randomized controlled trials (RCT), considered the "gold" standard for intervention research, have used a universal approach to prevention (Jimenez Barbero et al., 2016; Ttofi \& Farrington, 2011).

Targeted strategies are those that are "selective" (targeting youth who are at risk for engaging in bullying or targeting youth at risk of being bullied), or "indicated" (those that provide more intensive supports and activities for those who are already displaying bullying behavior or have a history of being bullied and are showing early signs of behavioral, academic, or mental health consequences). These components are layered onto or are combined with the universal intervention to address factors that may place youth at risk for being targets or perpetrators of bullying.

There is a lack of intervention research on programs related to cyberbullying and on programs targeted to vulnerable populations such as lesbian, gay, bisexual, and transgender (LGBT ${ }^{3}$ ) youth; youth with chronic health problems; or youth with developmental disabilities such as autism (Minton, 2014). The role of peers in interventions for at-risk students or for those who are perpetrators or targets needs further clarification and study. Moreover, few bullying

\footnotetext{
${ }^{3}$ Different acronyms (e.g., LGBT, LGB, etc.) are used depending on the evidence available. LGB refers to sexual identities, $T$ to gender identity, and $Q$ or Queer can refer to gender and sexuality.
} 


\section{Preventing Bullying}

programs include specific intervention components for youth at risk for involvement in bullying or for youth already involved in bullying, whether as perpetrators, targets, or both perpetrators and targets.

\section{Approaches to Avoid}

There are some approaches to intervening in or preventing bullying, that though well-intended, may be harmful or just simply ineffective. These include

- Suspension and related exclusionary techniques-These may result in increased academic and behavioral problems for youth and have generally been discouraged by knowledgeable experts.

- Encouraging youth to fight back when bullied-This suggests that aggression is an effective means for responding to victimization and may perpetuate the cycle of violence.

- Youth- or peer-facilitated programs, such as peer mediation, peer-led conflict resolution, forced apology, and peer mentoring-These may not be appropriate or effective in bullying prevention. Programs are rarely structured in a way to address peer abuse of power. These include

- Grouping youth who bully together-this may reinforce their aggressive behaviors and result in higher rates of bullying

- Conflict resolution approaches that bring youth who bully and the targets of bullying together face-to-face, which can end up "blaming the victim"

- One-day awareness-raising events or brief assemblies-There is little evidence that these are effective at changing a climate of bullying or producing sustainable effects on bullying behavior (see Farrington \& Ttofi, 2009).

- $\quad$ Linking bullying and suicide together directly-Practitioners, researchers and journalists should be cautious about highlighting such a potential link, as it may result in confusion and misattribution among families as well as in the media. It is critical to state the epidemiologic evidence that suicide is extremely complex and generally associated more directly with mental health concerns such as anxiety and depression. Bullying could serve as a risk factor for youth who are also experiencing mental health concerns (Klomek et al., 2011) but is not likely to be the only factor.

- Zero tolerance policies that use automatic suspensions-They may lead to underreporting of bullying incidents because the consequence of suspension is perceived as harsh or punitive. There is limited evidence that these policies are effective in curbing 
aggressive or bullying behavior (American Psychological Association Zero Tolerance Task Force, 2008; Boccanfuso \& Kuhfeld, 2011).

\section{How Youth Can Address Bullying}

How young people act is influenced by the attitudes and behavior of their peers as described earlier. Peer groups influence whether bullying happens. Some peer groups tolerate and even encourage bullying behavior, while others actively discourage it from happening. Having friends can protect a young person against being the target of bullying. To prevent or reduce bullying, youth can be aware that bullying has harmful consequences for everyone involved in bullying behavior, not just students who are the targets of bullying.

Young people can help prevent bullying in their schools by working with their school communities to implement effective bullying-prevention programs. For instance, gay-straight alliances can help buffer LGBT youth against bullying. These alliances are usually student-led, school-based clubs that aim to improve the school climate for LGBT youth and educate the school community about LGBT issues. Also, intervention programs that operate through peer bystander behavior are garnering increased attention. In a meta-analysis conducted by Polanin and colleagues (2012), the researchers found that bystander-involved models were generally effective at reducing bullying and that the effects of bystander interventions were stronger for students in high school than for students in younger grades. Youth can also learn more about their local and state laws and policies about bullying.

\section{How Parents Can Address Bullying}

A child or youth's connectedness to other people is a significant buffer against problems caused by being bullied. Families are one of the strongest influences on children's development. Because of this, families can also play a role in bullying prevention. Parents can and should recognize symptoms that may mean a child is being bullied, such as

- Physical injuries, headaches, sleep disturbances, or other physical symptoms that aren't fully explained by a known medical condition.

- Depression, anxiety, self-harming behavior (common for girls) and anger, aggression, and engagement in risky and impulsive behavior (more common for boys).

- Poorer grades or test scores than in prior years.

- Poor peer relationships, health problems, and aggression, which can occur both to perpetrators and targets. 


\section{Preventing Bullying}

Parents can also be aware that other factors in the home can increase the likelihood of youth being a perpetrator or target of bullying, such as domestic violence, abuse, and behavior such as bullying among siblings or cousins. Parents can create opportunities for positive social involvement in the family, which can lessen a child's chances of being involved in antisocial behavior such as perpetrating bullying. Parental support may protect teens from multiple forms of bullying, including cyberbullying. This can include spending time with their teens, talking through their worries, taking an interest in schoolwork, or helping with planning for the future. Parents can also get involved in implementing evidence-based, anti-bullying programs in their children's school, and can also learn more about anti-bullying laws and policies in their state and local school district. In the meta-analysis by Ttofi and Farrington (2009), the authors found that several family factors were important elements of effective bullying prevention programs, including parent training and informing parents about bullying.

\section{How Educators Can Address Bullying}

Because of the amount of time that children and youth spend in school and the overall rates of school-based bullying, teachers, school administrators, and school staff are in a unique position to promote healthy relationships and to intervene in bullying situations. Teachers can create a climate of support and empathy both inside and outside of the classroom. They often serve as frontline interveners in bullying situations as well as implementers of bullying prevention programs. However, there is often a disconnect between students' and educators' perceptions of bullying. Some studies have shown that educators underestimate the impact and prevalence of bullying. Also, both students and teachers report that teachers do not know how to intervene effectively, which prevents students from seeking help and contributes to teachers ignoring bullying. Professional development can have a positive effect in terms of increasing teachers' willingness to intervene in bullying incidents. Furthermore, fair discipline practices in schoolswhich consistently and fairly enforce rules-can reduce the amount of bullying that occurs.

In addition to recognizing the symptoms, described above, that may mean a child is being bullied, effective supervision, especially in bullying "hot spots" such as playgrounds, and clear anti-bullying policies are essential elements of a successful school-wide prevention effort. Having at least one trusted and supportive adult at school, which in many cases is a teacher, can help buffer LGBT youth who are bullied from displaying suicidal behaviors.

Teachers and other professionals need a more consistent, intentional, and evidence-based system of training to support their efforts to prevent bullying. In addition to offering 
multicomponent, school-wide programs, which combine elements of universal programs, such as providing class time to discuss bullying, along with more targeted interventions for youth at risk of bullying or being bullied-for example, teaching more intensive social-emotional skills, bullying prevention programs should include efforts to enhance resilience and positive behaviors and not just focus on reducing bullying. Like youth and parents, teachers, administrators, and staff should be aware of anti-bullying laws and policies in their states and local school districts.

\section{How Youth Workers Can Address Bullying}

Although bullying has been mostly studied within the school context, youth workers can play a critical role in creating a climate of support and empathy outside of the classroom. These individuals may be implementers of programs and frontline interveners in bullying situations and can learn to recognize symptoms related to engagement in bullying behavior. Professionals and volunteers who work directly with children and youth regularly can benefit from training that occurs on an ongoing basis to ensure retention of information and to sustain competence. This also accounts for the turnover of personnel and promotes high-quality implementation of evidence-informed bullying prevention practices.

\section{How Health Care Providers Can Address Bullying}

Health care clinicians, including mental and behavioral health experts, can be important players in bullying prevention, especially when they can collaborate with teachers and other education professionals. Evidence of the physical, mental, and behavioral health issues of children who bully, who are bullied, or who observe bullying incidents provides child health and mental health clinicians in community and acute care settings with knowledge to engage in bullying prevention interventions. Clinicians in schools, clinics, primary care practices, schools, and school-based health centers have opportunities to discuss bullying during visits for well childcare, annual school or sports exams, and routine acute care. As mentioned previously, children and youth who bully may have specific health care needs. They might also have family situations that are characterized by violence, abuse, neglect, low socioeconomic status, or other stressful issues. Perpetrating bullying might be the manifestation of other underlying issues such as mental or behavioral health problems, alienation, homelessness, or undetected learning disabilities.

Because some children and youth internalize victimization or emotional difficulties, the physical or emotional impacts of bullying on children who bully, have been bullied, or have been 


\section{Preventing Bullying}

bystanders to bullying might not be readily apparent to family members, educators, or health care professionals. Therefore, during child health encounters, clinicians might inquire about changes in behavior, appetite, and sleep, and about children's attitudes toward school as ways of screening for involvement with bullying, as well as confidentially directly asking the adolescent. Health care professionals might also consider protective factors for youth involved with bullying and could guide parents and children about the importance of certain supports, including parents, friends, and nonparental adults.

Since most bullying occurs at school, school nurses and counselors are often on the frontlines of caring for children and youth involved in bullying. They might be the first health care professional involved with children and youth who have been bullied in school settings, especially some groups of children who are particularly at risk. Clinicians should inquire about bullying, even when the youth presents with symptoms that seem consistent with other mental health problems, as bullying may be a contributing factor. Bullying prevention and intervention presents inherent challenges to pediatric health care providers. If a health care professional suspects or identifies a child who has been involved with bullying, effective mechanisms for referral and collaboration with education and other professionals are typically lacking. Organizations such as the American Academy of Pediatrics and the National Association of School Nurses have issued statements on the bullying prevention role of their respective members. Pediatricians, school nurses, and school counselors should be among the school personnel who are trained on the implementation of evidence-informed bullying prevention.

\section{Conclusion}

While the study of bullying behavior is a relatively recent field, much has been learned over the past few decades that has significantly improved the evidence-based knowledge of what bullying behavior is, how it can be measured, and the contexts that can ameliorate or potentiate the association between individual characteristics and being a bully, a target of bullying, or a bystander to the bullying behavior. Research has established that bullying negatively impacts the child who is bullied, the child who bullies, the child who both bullies and is a target, and the bystanders. Research is also starting to show ways in which law and policy can play an important role in strengthening state and local efforts to prevent, identify, and respond to bullying. This is a key time for bullying prevention, and there is not a quick fix or one-size-fits-all solution. Reducing the presence and impact of bullying in youths' lives will 
Journal of Youth Development | http://jyd.pitt.edu/ | Vol. 15 Issue 3 DOI 10.5195/jyd.2020.945

Preventing Bullying

involve multifaceted efforts at both the state and federal levels, and will need to engage governments, communities, schools, families, health care, media, and social media.

\section{References}

American Psychological Association Zero Tolerance Task Force. (2008). Are zero tolerance policies effective in the schools?: An evidentiary review and recommendations. American Psychologist, 63(9) 852-862. https://doi.org/10.1037/0003-066X.63.9.852

Beran, T. (2009). Correlates of peer victimization and achievement: An exploratory model. Psychology in the Schools, 46(4), 348-361. https://doi.org/10.1002/pits.20380

Beran, T. N., Hughes, G., \& Lupart, J. (2008). A model of achievement and bullying: Analyses of the Canadian National Longitudinal Survey of Children and Youth data. Educational Research, 50(1), 25-39. https://doi.org/10.1080/00131880801920379

Beran, T. N., \& Lupart, J. (2009). The relationship between school achievement and peer harassment in Canadian adolescents: The importance of mediating factors. School Psychology International, 30(1), 75-91. https://doi.org/10.1177/0143034308101851

Boccanfuso, C., \& Kuhfeld, M. (2011, March). Multiple responses, promising results: Evidence-based nonpunitive alternatives to zero tolerance (Research to Results Brief, Child Trends Publication No. 2011-09). http://www.childtrends.org/wp-content/uploads/2011/03/Child Trends-

\section{RB AltToZeroTolerance.pdf}

Bradshaw, C. P. (2015). Translating research to practice in bullying prevention. American Psychologist, 70(4), 322. https://doi.org/10.1037/a0039114

de Bruyn, E., Cillessen, A., \& Wissink, I. (2010). Associations of peer acceptance and perceived popularity with bullying and victimization in early adolescence. Journal of Early Adolescence, 30(4), 543566. https://doi.org/10.1177/0272431609340517

Dijkstra, J. K., Lindenberg, S., \& Veenstra, R. (2008). Beyond the class norm: Bullying behavior of popular adolescents and its relation to peer acceptance and rejection. Journal of Abnormal Child Psychology, 36(8), 1289-1299. https://doi.org/10.1007/s10802-008-9251-7

Faris, R., \& Ennett, S. (2012). Adolescent aggression: The role of peer group status motives, peer aggression, and group characteristics. Social Networks, 34(4), 371-378. https://doi.org/10.1016/j.socnet.2010.06.003

Farmer, T. W., Estell, D. B., Bishop, J. L., O’Neal, K. K., \& Cairns, B. D. (2003). Rejected bullies or popular leaders? The social relations of aggressive subtypes of rural African American early adolescents. Developmental Psychology, 39(6), 992-1004. https://doi.org/10.1037/0012$\underline{1649.39 .6 .992}$ 
Farrington, D. P., \& Ttofi, M. (2009). School-based programs to reduce bullying and victimization: A systematic review. Campbel/ Systematic Reviews, 5(6), 1-148. https://doi.org/10.4073/csr.2009.6

Gini, G., \& Pozzoli, T. (2009). Association between bullying and psychosomatic problems: A metaanalysis. Pediatrics, 123(3), 1059-1065. https://doi.org/10.1542/peds.2008-1215

Gladden, R. M., Vivolo-Kantor, A. M., Hamburger, M. E., \& Lumpkin, C. D. (2014). Bullying surveillance among youths: Uniform definitions for public health and recommended data elements (Version 1.0). Centers for Disease Control and Prevention and U.S. Department of Education. https://files.eric.ed.gov/fulltext/ED575477.pdf

Glew, G. M., Fan, M.-Y., Katon, W., Rivara, F. P., \& Kernic, M. A. (2005). Bullying, psychosocial adjustment, and academic performance in elementary school. Archives of Pediatrics and Adolescent Medicine, 159(11), 1026-1031. https://doi.org/10.1001/archpedi.159.11.1026

Hatzenbuehler, M. L., \& Keyes, K. M. (2013). Inclusive anti-bullying policies and reduced risk of suicide attempts in lesbian and gay youth. Journal of Adolescent Health, 53(1), S21-S26. https://doi.org/10.1016/j.jadohealth.2012.08.010

Institute of Medicine. (1994). Reducing risks for mental disorders: Frontiers for preventive intervention research. National Academy Press.

Jiménez-Barbero, J. A., Ruiz-Hernández, J. A., Llor-Zaragoza, L., Pérez-García, M., \& Llor- Esteban, B. (2016). Effectiveness of anti-bullying school programs: A meta-analysis. Children and Youth Services Review, 61, 165-175. https://doi.org/https://doi.org/10.1016/j.childyouth.2015.12.015

Juvonen, J., Nishina, A., \& Graham, S. (2000). Peer harassment, psychological adjustment, and school functioning in early adolescence. Journal of Educational Psychology, 92(2), 349-359. https://doi.org/10.1037/0022-0663.92.2.349

Klomek, A. B., Kleinman, M., Altschuler, E., Marrocco, F., Amakawa, L., \& Gould, M. S. (2011). High school bullying as a risk for later depression and suicidality. Suicide and Life-Threatening Behavior, 41(5), 501-516. https://doi.org/10.1111/j.1943-278X.2011.00046.x

Kochenderfer, B. J., \& Ladd, G. W. (1996). Peer victimization: Cause or consequence of school maladjustment? Child Development, 674), 1305-1317. https://doi.org/10.1111/j.14678624.1996.tb01797.x

Kowalski, R. M., and Limber, S. P. (2013). Psychological, physical, and academic correlates of cyberbullying and traditional bullying. Journal of Adolescent Health, 53(1), S13-S20. https://doi.org/10.1016/j.jadohealth.2012.09.018

Lereya, S. T., Copeland, W. E., Costello, E. J., \& Wolke, D. (2015). Adult mental health consequences of peer bullying and maltreatment in childhood: Two cohorts in two countries. The Lancet Psychiatry, 2(6), 524-531. https://doi.org/10.1016/S2215-0366(15)00165-0 
Limber, S. B. (2014). Bullying Among Children and Youth. Unpublished manuscript of a study commissioned by the Planning Committee on Increasing Capacity for Reducing Bullying and Its Impact on the Lifecourse of Youth Involved. Department of Psychology and Institute on Family and Neighborhood Life, Clemson University.

Marsh, H. W., Nagengast, B., Morin, A. J., Parada, R. H., Craven, R. G., \& Hamilton, L. R. (2011). Construct validity of the multidimensional structure of bullying and victimization: An application of exploratory structural equation modeling. Journal of Educational Psychology, 103(3), 701-732. https://doi.org/10.1037/a0024122

McDougall, P., \& Vaillancourt, T. (2015). Long-term adult outcomes of peer victimization in childhood and adolescence: Pathways to adjustment and maladjustment. American Psychologist, 70(4), 300. https://doi.org/10.1037/a0039174

Minton, S. J. (2014). Prejudice and effective anti-bullying intervention: Evidence from the bullying of "minorities." Nordic Psychology, 66(2), 108-120. https://doi.org/10.1080/19012276.2014.928485

Musher-Eizenman, D. R., Boxer, P., Danner, S., Dubow, E. F., Goldstein, S. E., \& Heretick, D. M. L. (2004). Social-cognitive mediators of the relation of environmental and emotion regulation factors to children's aggression. Aggressive Behavior, 30(5), 389-408.

Nakamoto, J., \& Schwartz, D. (2010). Is peer victimization associated with academic achievement? A meta-analytic review. Social Development, 19(2), 221-242.

National Academies of Sciences, Engineering, and Medicine. 2016. Preventing bullying through science, policy, and practice. The National Academies Press. https://doi.org/10.17226/23482

Neary, A., \& Joseph, S. (1994). Peer victimization and its relationship to self-concept and depression among schoolgirls. Personality and Individual Differences, 16(1), 183-186. https://doi.org/10.1016/0191-8869(94)90122-8

Nixon, C. (2014). Current perspectives: The impact of cyberbullying on adolescent health. Adolescent Health, Medicine and Therapeutics, 143-158. https://doi.org/10.2147/AHMT.S36456

Olweus, D. (1993a). Bullying at school. What we know and what we can do. Oxford, UK: Blackwell.

Olweus, D. (1993b). Victimization by peers: Antecedents and long-term outcomes. In K. H. Rubin \& J. B. Asendorpf (Eds.), Social Withdrawal, Inhibition, and Shyness in Childhood (pp. 315-341). Psychology Press.

Olweus, D. (2001). Peer harassment: A critical analysis and some important issues. In J. Juvonen \& S. Graham (Eds.), Peer harassment in school: The plight of the vulnerable and victimized (pp. 320). Guilford Press.

Peeters, M., Cillessen, A. H., \& Scholte, R. H. (2010). Clueless or powerful? Identifying subtypes of bullies in adolescence. Journal of Youth and Adolescence, 39(9), 1041-1052. https://doi.org/10.1007/s10964-009-9478-9 
Polanin, J. R., Espelage, D. L., \& Pigott, T. D. (2012). A meta-analysis of school-based bullying prevention programs' effects on bystander intervention behavior. School Psychology Review, 41(1), 47-65.

Pöyhönen, V., Juvonen, J., \& Salmivalli, C. (2010). What does it take to stand up for the victim of bullying? The interplay between personal and social factors. Merrill-Palmer Quarterly, 56(2), 143163.

Reijntjes, A., Kamphuis, J. H., Prinzie, P., \& Telch, M. J. (2010). Peer victimization and internalizing problems in children: A meta-analysis of longitudinal studies. Child Abuse \& Neglect, 34(4), 244252. https://doi.org/10.1016/j.chiabu.2009.07.009

Rigby, K., \& Slee, P. T. (1993). Dimensions of interpersonal relation among Australian children and implications for psychological well-being. Journal of Social Psychology, 133(1), 33-42.

\section{https://doi.org/10.1080/00224545.1993.9712116}

Rigby, K., \& Slee, P. (2008). Interventions to reduce bullying. International Journal of Adolescent Medicine and Health, 20(2), 165-183. https://doi.org/10.1515/IJAMH.2008.20.2.165

Rivers, I., \& Noret, N. (2013). Potential suicide ideation and its association with observing bullying at school. Journal of Adolescent Health, 53(1), S32-S36.

https://doi.org/10.1016/j.jadohealth.2012.10.279

Rivers, I., Poteat, V. P., Noret, N., \& Ashurst, N. (2009). Observing bullying at school: The mental health implications of witness status. School Psychology Quarterly, 24(4), 211-223. https://doi.org/10.1037/a0018164

Rodkin, P. C., Espelage, D. L., \& Hanish, L. D. (2015). A relational framework for understanding bullying: Developmental antecedents and outcomes. American Psychologist, 70(4), 311-321. https://doi.org/10.1037/a0038658

Salmivalli, C. (2001). Group view on victimization: Empirical findings and their implications. In J. Juvonen \& S. Graham (Eds.), Peer harassment in school (pp. 398-419). Guilford Press.

Salmivalli, C. (2010). Bullying and the peer group: A review. Aggression and Violent Behavior, 15(2), 112120. https://doi.org/10.1016/j.avb.2009.08.007

Salmivalli, C. (2014). Participant roles in bullying: How can peer bystanders be utilized in interventions? Theory Into Practice, 53(4), 286-292. https://doi.org/10.1080/00405841.2014.947222

Sijtsema, J. J., Veenstra, R., Lindenberg, S., \& Salmivalli, C. (2009). Empirical test of bullies' status goals: Assessing direct goals, aggression, and prestige. Aggressive Behavior, 35, 57-67. https://doi.org/10.1002/ab.20282

Thunfors, P., \& Cornell, D. (2008). The popularity of middle school bullies. Journal of School Violence, Л1), 65-82. https://doi.org/10.1300/J202v07n01 05 
Preventing Bullying

Trach, J., Hymel, S., Waterhouse, T., \& Neale, K. (2010). Bystander responses to school bullying: A cross-sectional investigation of grade and sex differences. Canadian Journal of School Psychology, 25(1), 114-130. https://doi.org/10.1177/0829573509357553

Ttofi, M. M., \& Farrington, D. P. (2009). What works in preventing bullying: Effective elements of antibullying programmes. Journal of Aggression, Conflict and Peace Research, 1(1), 13-24. https://doi.org/10.1108/17596599200900003

Ttofi, M. M., \& Farrington, D. P. (2011). Effectiveness of school-based programs to reduce bullying: A systematic and meta-analytic review. Journal of Experimental Criminology, 7(1), 27-56. https://doi.org/10.1007/s11292-010-9109-1

Ttofi, M. M., Farrington, D. P., Lösel, F., \& Loeber, R. (2011). Do the victims of school bullies tend to become depressed later in life? A systematic review and meta-analysis of longitudinal studies. Journal of Aggression, Conflict and Peace Research, 3(2), 63-73. https://doi.org/10.1108/17596591111132873/full/html

Vaillancourt, T., Hymel, S., \& McDougall, P. (2003). Bullying is power: Implications for school-based intervention strategies. Journal of Applied School Psychology, 19(2), 157-176. https://doi.org/10.1300/J008v19n02 10

Vaillancourt, T., McDougall, P., Hymel, S., \& Sunderani, S. (2010). The relationship between power and bullying behavior. In S. R. Jimerson, S. M. Swearer, \& D. L. Espelage (Eds.), Handbook of Bullying in Schools: An International Perspective (pp. 211-222). Routledge.

Vaillancourt, T., Brittain, H. L., McDougall, P., \& Duku, E. (2013). Longitudinal links between childhood peer victimization, internalizing and externalizing problems, and academic functioning: Developmental cascades. Journal of Abnormal Child Psychology, 41(8), 1203-1215. https://doi.org/10.1007/s10802-013-9781-5

Valkenburg, P. M., \& Peter, J. (2011). Online communication among adolescents: An integrated model of its attraction, opportunities, and risks. Journal of Adolescent Health, 48(2), 121-127. https://doi.org/10.1016/j.jadohealth.2010.08.020

Vreeman, R. C., \& Carroll, A. E. (2007). A systematic review of school-based interventions to prevent bullying. Archives of Pediatrics and Adolescent Medicine, 161(1), 78-88.

Wolke, D., \& Lereya, S. T. (2015). Long-term effects of bullying. Archives of Disease in Childhood, 100(9), 879-85. https://doi.org/10.1136/archdischild-2014-306667

Wolke, D., Lereya, S. T., Fisher, H., Lewis, G., \& Zammit, S. (2014). Bullying in elementary school and psychotic experiences at 18 years: A longitudinal, population-based cohort study. Psychological Medicine, 44(10, 2199-2211. https://doi.org/10.1017/S0033291713002912 
Journal of Youth Development | http://jyd.pitt.edu/ | Vol. 15 Issue 3 DOI 10.5195/jyd.2020.945

\section{Preventing Bullying}

Ybarra, M. L., \& Mitchell, K. L. (2004). Online aggressor/targets, aggressors, and targets: A comparison of associated youth characteristics. Journal of Child Psychology and Psychiatry, 45(7), 1308-1316. https://doi.org/10.1111/j.1469-7610.2004.00328.x 